\title{
Pedagogia do Esporte: livro didático aplicado aos Jogos Esportivos Coletivos
}

\author{
Larissa Rafaela Galatti ${ }^{1,2}$ \\ Roberto Rodrigues Paes ${ }^{2}$ \\ Suraya Cristina Darido ${ }^{3}$ \\ ${ }^{1}$ Universidade Nove de Julho e IASP/Universidade Adventista de São Paulo, SP, Brasil \\ 2 Faculdade de Educação Física da UNICAMP, Campinas, SP, Brasil \\ ${ }^{3}$ Instituto de Biociências. UNESP - Univ Estadual Paulista, Campus de Rio Claro, \\ Departamento de Educação Física, Rio Claro, SP, Brasil
}

\begin{abstract}
Resumo: $O$ estudo trata das possibilidades pedagógicas do livro didático (LD) como recurso nas aulas de Educação Física, tendo por conteúdo o esporte e, em específico, os jogos esportivos coletivos (JECs). Foi desenvolvida uma revisão bibliográfica dos termos citados e, a partir desta, o estudo avança para a proposição de um livro didático em educação física na temática dos JECs, considerando dois referenciais: um técnico-tático e outro sócio-educativo. Para tal, recorremos a métodos provenientes da área da lingüística, com o desenvolvimento de uma Seqüência Didática que permitiu a seleção e distribuição dos conteúdos a serem apresentados no LD de forma ordenada e criteriosa. O foco nos JECs se justifica pela sua inserção sócio-cultural e pela necessidade de transformar estudos mais recentes em novos procedimentos pedagógicos para a prática dessas modalidades. O livro didático, bem como a preparação adequada dos profissionais que o utilizarão, é apontado como facilitador no processo de ensino, vivência e aprendizagem dos jogos esportivos coletivos.
\end{abstract}

Palavras-chave: Pedagogia do Esporte. Educação Física. Jogos Esportivos Coletivos. Livro Didático.

\section{Sport Pedagogy: text books applied to team sports}

\begin{abstract}
The study deals with the pedagogical possibilities of text books as a resource for Physical Education (PE) classes based on sports, specifically team sports. It started from a bibliographical review on the cited terms and after that we advanced our studies in order to propose a didactic text book on Team Sports for PE classes considering two benchmarks: one technical-tactic and the other social-educational. In order to do so, we used methods from linguistics, and the development of a Didactic Sequence allowed the selection and distribution of the contents to be presented in the book in an orderly and judicious way. The focus in Team Sports is justified by its social-cultural insertion and by the need to transform recent studies into new pedagogical procedures for practicing them. The didactic text book, as well as the adequate preparation of the professionals who will use it, is pointed out as facilitator in the process of teaching, experiencing and learning team sports.
\end{abstract}

Key Words: Sport Pedagogy. Physical Education. Team sports. Textbook.

\section{Introdução}

A Educação Física, enquanto disciplina escolar, apresenta variados conteúdos, tais quais o esporte, o jogo, a ginástica e atividades circenses, a dança, a luta, entre outros. Entretanto, observa-se a prevalência do conteúdo esporte, em especial dos jogos esportivos coletivos (JECs), como apontam Paes (2001) e Rosário e Darido (2005); dentre estes, destacamse o basquetebol, futsal, handebol e voleibol.

Certamente ampliar os conteúdos abordados no ensino formal para além dos JECs é uma necessidade atual, entretanto, faz-se também necessário melhor organizar o processo de ensino e aprendizagem dos JECs, buscando dar a estes um tratamento pedagógico coerente com o ensino formal, assim como seqüenciar didaticamente os conhecimentos pertinentes aos JECs, ampliando sua presença na escola para além das questões técnicas-táticas de modalidades isoladas.

$\mathrm{Na}$ expectativa de tratar dos jogos esportivos coletivos a partir de sua evolução histórica e contextos culturais que os justifiquem no ambiente escolar, passamos a pesquisar um recurso didático que pudesse ser agregado à prática pedagógica do professor, sendo mais um mediador no processo de ensino, vivência e aprendizagem dos JECs. Em pesquisa 
bibliográfica, optamos pela proposição de um livro didático (LD) buscando estruturá-lo a partir dos elementos comuns dos JECs (BAYER, 1994), para um posterior aprofundamento e modalidades específicas.

A concepção de uma proposta de Livro Didático para aulas de Educação Física, com foco nos JECs, só foi possível a partir do aprofundamento no estudo do livro didático, a fim conhecermos este recurso didático para podermos construí-lo com maior competência. Isto foi possível através da aproximação dos estudos em educação física aos autores ligados à lingüística, em especial Dolz, Noverraz \& Schneuwly (2004), autores franceses que apresentam exigências para 0 ensino de expressão oral e escrita que transferimos para 0 esporte, buscando, sobretudo, levantar pressupostos para a construção de uma proposta de ensino dos JECs com o auxílio do LD, sendo aqui apontados alguns, como:

- Permitir o ensino dos JECs a partir de suas semelhanças, mas sem desconsiderar as diferenças que caracterizam cada modalidade que compõem este grupo;

- Oferecer um material de apoio escrito rico em textos de referência, nos quais os alunos possam apoiar-se para construir suas próprias reflexões e conclusões,

- Que este material escrito apresente-se, preferencialmente, em módulos, para permitir uma diferenciação de ensino;

- Favorecer a elaboração de projetos em grupo, com a interação de toda a classe;

- Centrar-se, de fato, nas dimensões práticas e teóricas dos JECs, enfatizando as possibilidades de aprendizagem social.

A partir de tais pressupostos, reforçamos a opção pelo livro didático, por suas características pedagógicas e, em especial, pela importância que a mediação do professor tem no uso deste gênero literário. Neste estudo, consideramos o livro didático elaborado para 0 aluno, cuja utilização deve ser mediada pelo professor, sendo indicado, para tal, um livro do professor com papel orientador (LAJOLO, 1996). Esta proposta não pretende ser única ou dar conta de todas as possibilidades de ensino e aprendizagem dos JECs, mas, com ênfase no estudo do livro didático e suas possíveis contribuições para o processo de ensino e aprendizagem do esporte e em especial dos JECs, pretende-se oferecer múltiplas situações de leitura, fala e de prática envolvendo os JECs, a fim de criar um ambiente de ensino, vivência e aprendizagem capaz de lidar com a complexidade do fenômeno.

\section{Livro Didático em Educação Física e o foco nos JECs: Justificativa, organização e sistematização}

Sendo o esporte um dos maiores fenômenos sócio-culturais da contemporaneidade, mostra-se relevante sua prática e reflexão na educação formal, uma vez que Paes (2001) aponta a importância da escola na democratização do acesso ao esporte, desde que sistematizado como um conteúdo da Educação Física. $\mathrm{O}$ autor afirma que as discussões e avanços acadêmicos têm sido intensos na área da Educação Física Escolar, ficando, entretanto, distantes do cotidiano do professor que atua na escola.

Em pesquisa realizada em 1996, Paes (1997) percebeu a necessidade dos professores em acessar trabalhos que possam ser aplicados na prática, a fim de que mudanças possam de fato acontecer; sinaliza também para a necessidade de serem ofertadas ao professor de Educação Física subsídios pedagógicos para o trato com o esporte. E este é um dos objetivos deste estudo: oferecer um facilitador pedagógico para o professor de Educação Física no trato com o esporte, sendo apontado neste artigo, como uma possibilidade, a inserção de livros didáticos (LD) nesta disciplina.

Esse recurso didático, ainda pouco disseminada na cultura escolar em relação à Educação Física, ganha importante na contemporaneidade, como demonstra a iniciativa do Governo do Estado de São Paulo que incluiu, em 2009, o caderno didático de Educação Física no seu programa de material didático nas escolas de todo o estado. Em nível nacional, a inclusão da disciplina de Educação Física entre as contempladas pelo Programa Nacional do Livro Didático, do Ministério da Educação, é outra evidência da emergente necessidade de intensificação dos estudos relacionam este recurso didático à Educação Física. 
A proposta deste ensaio e discutir a elaboração de um livro didático que ofereça ao professor e ao aluno um referencial que una a prática do esporte com o seu estudo teórico, abordando não apenas as questões técnicotáticas e sua prática, mas também aspectos teóricos e históricos do esporte, associados à percepção dos valores morais e questões educacionais relacionados ao fenômeno, integrando, desta forma, as dimensões conceitual, procedimental e atitudinal deste conteúdo da Educação Física (DARIDO e SANCHES NETO, 2005)

Considerando, ainda, que a pesquisa de $\underline{\text { Paes }}$ (1997) revelou que a maioria dos professores trabalhava a maior parte do tempo com 0 conteúdo esporte e em especial com a modalidades coletivas futebol, voleibol, basquetebol e handebol (nesta ordem), o LD aqui proposto terá ênfase nos Jogos Esportivos Coletivos (JECs). Certamente outros estudos e novas propostas serão necessários abordando outros conteúdos, para que as necessidades da escola e sobretudo dos alunos sejam atendidas.

Paes (2001) afirma que o binômio Educação Física/Esporte gerou alguns equívocos durante as décadas de 1970 e 80 , relatando que, em geral, a escola oferecia o Esporte de forma fragmentada, repetitiva e seletiva, sem grandes preocupações educacionais, contribuindo pouco para o desenvolvimento do aluno enquanto cidadão, que é uma das principais metas da escola, como também destaca Betti (1991. p.100), referindo-se ao período a partir das décadas de 1960 e 70 quando a Educação Física e o esporte passam a confundir-se.

O período assinalou a ascensão do esporte à razão do Estado e a inclusão do binômio Educação Física/Esporte na planificação estratégica dos governos. Ocorreram também profundas mudanças na política educacional e na Educação Física Escolar, que se subordinou ao sistema formador de recursos humanos para a Educação Física e o Esporte.

Paes (1997) destaca que, nos anos de 1990, esta prática ainda podia ser verificada na escola, sendo a aula de Educação Física, muitas vezes, um conjunto de repetições de técnicas fragmentadas e descontextualizadas de técnicas esportivas, feita com fim em si mesma, não como um caminho para a educação do cidadão. Em contraponto à essa prática, na década de 2000, Darido e Sanchez Neto (2005) identificam a emersão da oferta esportiva no contexto escolar a partir da prática do "dar a bola", também denominada de "jogo livre", ou recreacionista (KUNZ, 1997) em que os alunos praticam livremente a modalidade esportiva escolhida sem a intervenção pedagógica do professor. Os autores levantam duas principais razões para a substituição de uma prática problemática (o excesso da técnica) por outra ( a ausência de intervenção do professor): a ênfase da comunidade acadêmica no que não se deve fazer na Educação Física, sem propostas viáveis para a prática, e a falta de políticas públicas que facilitem e dêem ao professor melhores condições de trabalho (DARIDO E SANCHEZ NETO, 2005).

A fim possibilitar uma melhor compreensão do fenômeno esporte - e de forma mais específica dos JECs - e contribuir com propostas exeqüíveis para a prática do professor de Educação Física é que propomos o livro didático, buscando ampliar as possibilidades de trato com esporte no ambiente escolar, como destaca Paes (2001, p.40):

(...) o esporte, como conteúdo da Educação Física na escola, deverá ser oferecido de forma que o aluno possa compreendê-lo integralmente, conhecendo suas diferentes modalidades; seu ensino deverá abranger conhecimentos teóricos e práticos, dando oportunidade ao aluno de aprender e vivenciar seus fundamentos, compreender suas regras, bem como conhecer sua história e evolução.

O estudo dos JECs acompanhado de um livro didático permite ao aluno ter contato, de forma mais sistematizada, com a história e evolução do esporte enquanto fenômeno e de modalidades esportivas; pode ter acesso às regras a partir de uma linguagem mais adequada, diferente daquela utilizada nos livros de regras oficiais das federações e confederações esportivas; pode conhecer os fundamentos, ou seja, diferentes possibilidades técnicas, mas sem desvinculá-los da tática, das estratégias de jogo, já que 
consideramos os fundamentos como ferramentas para se resolver os problemas propostos pelo jogo, portanto, incluídos no jogo e não maiores que este. Em uma linguagem adequada ao público infato-juvenil, o LD pode, ainda, otimizar as possibilidades educacionais do esporte.

Betti (1992, p.286) também aborda a Educação Física em sua função pedagógica, ampliando as possibilidades educacionais através do esporte, que entendemos poderem ser otimizadas por um livro didático que considere pontos importantes como os apontados pelo autor no trecho que se segue:

Não basta aprender as habilidades motoras específicas do basquetebol; é preciso aprender a organizar-se socialmente para jogar, compreender as regras como elemento que torna o joga possível (...), aprender a respeitar o adversário como um companheiro e não como um inimigo a ser aniquilado, pois sem ele simplesmente não há jogo... É preciso, enfim, que o aluno seja preparado apara incorporar 0 basquetebol e a corrida na sua vida, para deles tirar o melhor proveito possível.

Assim, mais do que ensinar o esporte, o LD pode contribuir para que o aluno o compreenda, através de leituras e atividades didáticas a serem realizadas durante ou após a aula, com ou sem o acompanhamento do professor, mas sempre mediado por este, já que, como define Munakata (1999, p.579), a relação professor-aluno no uso do LD é tão peculiar que "se um aparecer sem o outro pode-se até mesmo dizer que o livro didático deixa de sê-lo".

Ressaltamos que não estamos desconsiderando a importância das atividades práticas no processo, tão pouco as diminuindo. Ao contrário, sem prática não há Educação Física, não há esporte e não há o porquê de propormos e desenvolvermos um LD neste sentido. Reforçamos a idéia de complementaridade, de agregarmos às atividades práticas do professor de Educação Física, ao lidar com os JECs, um material didático escrito, concreto, que o oriente na discussão dos temas ligados às questões técnicas, táticas, de regras, de valores morais, entre outros; oriente 0 professor, não determine sua prática, pois a autonomia deste é essencial para que sejam respeitadas as características e necessidades de cada grupo de alunos com qual este trabalha.

\section{Jogos Esportivos Coletivos: selecionando temas para o Livro Didático}

Para apontarmos diferentes temas de estudo que os JECs permitem, recorreremos a Bayer (1994), que aponta seis invariantes entre todos os JECs, sendo elas:

(1) Um objeto esférico a ser lançado pelo indivíduo com a mão, o pé ou com o auxílio de um instrumento;

(2) Um espaço demarcado de jogo, limite de ação de quem joga;

(3) Um alvo a ser atacado ou defendido;

(4) Os integrantes de uma equipe, que ajudam a progressão da bola com diferentes partes do corpo;

(5) Adversários que devem ser vencidos;

(6) Regras do jogo a serem respeitadas.

Os JECs, além destas características, possuem uma lógica interna regida pelas regras específicas de cada jogo, as quais podem ser modificadas em contextos não profissionais de prática, o que é indicado na iniciação esportiva, para que o jogo se adeque às possibilidades dos praticantes (PAES, 2001).

Gréhaine \& Guillon (1992) apud Garganta (1995) apontam como problema fundamental dos JECs a situação de oposição - como já destacava Teodorescu (1984) - que deve coordenar as ações com finalidade de recuperar, conservar e fazer progredir a bola, tendo como objetivo criar situações de finalização e marcar gols ou pontos. Bayer (1994) aborda os JECs de forma semelhante, partindo da possibilidade do "transfert", ou seja, transferência dos conhecimentos de um jogo para os demais. Desta forma, a partir das características comuns apresentadas há pouco, ele avança para os conceitos de "princípios operacionais" e de "regras de ação".

Os princípios operacionais de Bayer se dividem em defensivos e ofensivos, sendo os defensivos: proteger 0 alvo; impedir a progressão do adversário e recuperar a posse de bola. Quanto aos ofensivos, estes envolveriam: conservar a posse de bola; progredir em direção 
ao alvo e finalizar e marcar pontos. Ferreira, Galatti e Paes (2005, p.130) acrescentam princípios operacionais também para a transição, que é a passagem da quadra defensiva para a ofensiva ou da ofensiva para a defensiva.

Quanto ao conceito de regras de ação, estas se constituem como as estratégias que os jogadores, agora dentro de cada modalidade, estabelecem para atingir os objetivos propostos a partir dos princípios operacionais, tais como estabelecer linhas de passe e ocupar espaços vazios no ataque ou distribuir-se na quadra defensiva. Assim, Bayer (1994) aponta que é a partir das regras de ação que as modalidades esportivas coletivas passam a diferenciar-se, a tomar seus contornos específicos de ações, com o conseqüente surgimento de gestos técnicos específicos de cada modalidade

A base destes gestos técnicos podem alocarse, também, como elementos comuns entre os JECs, na medida em que há uma exigência de habilidades comuns, que posteriormente se desenvolveriam em técnicas específicas de cada modalidade, ou seja, os fundamentos (TANI, SANTOS e MEIRA JR., 2006). As habilidades seriam exigidas em cinco situações recorrentes nos diferentes JECs: controlar o corpo, manejar a bola, conduzir a bola (drible), passar a bola e finalizar em direção ao alvo.

Entretanto, o processo de ensino, vivência e aprendizagem em JECs não deve restringir-se aos aspectos técnico-táticos, mas deve preocupar-se também em possibilitar experiências relativas aos aspectos afetivosociais, sendo necessário que estes se apresentem como conteúdos sistematizados também no livro didático.

Galatti et. al. (2008) afirma que tão importante quanto organizar, sistematizar, aplicar e avaliar procedimentos pedagógicos para os componentes técnico-táticos dos JECs é fazê-lo em relação aos componentes sócio-educativos. Garganta (1995) considera o contexto dos JECs, pela interação humana que contempla, como de excelência para 0 trato com estes dois referenciais, destacando o papel do professor na composição deste ambiente formativo. Balbino (2001), Santana (2005) e Ferreira (2009) corroboram com a perspectiva, e sinalizam para a intencionalidade do professor no fomento a valores e modos de comportamento a partir do esporte e, em especial, dos JECs.
Observamos, que tão importante quanto as possibilidades de desenvolvimento motor pelo esporte, reforça-se seu caráter cognitivo; mais que isso, hoje se observa na prática esportiva e, em especial, dos JECs, um ambiente promotor do desenvolvimento afetivo e social, justamente pela necessidade de cooperação que tais modalidades imputem. Com isso, na composição de um LD na temática dos JECs consideramos dois referenciais, inicialmente sinalizados por Paes (2002): o metodológico, já abordado e o sócio-educativo, que a partir dos autores supracitados contemplam:

- Promoção da discussão de princípios, valores e modos de comportamento;

- Promoção da participação, inclusão, diversificação, co-educação e a autonomia;

- Proposição da troca de papéis (colocarse no lugar do outro);

- Construção de um ambiente favorável para desenvolvimento de relações intrapessoais e interpessoais (coletivas);

- Estabelecimento de relações entre o que acontece na aula de esportes com a vida em comunidade.

A partir de todo o referencial teórico tratado até aqui, apresentamos a seguir um quadro balizador dos conteúdos relacionados ao ensino do esporte tendo por eixo foco os JECs e a interação do LD com as aulas práticas, sendo apresentados os objetivos e competências a serem atingidos com os mesmos, acompanhados de estratégias possíveis para diferentes dinâmicas e seus exemplos.

Vale destacar que este quadro é um direcionador possível, não sendo capaz de abranger todas as possibilidades de trato com o esporte e nem mesmo com os JECs, corroborando com Rojo (1999, p.7), para quem, em relação à seleção dos conteúdos e atividades e a delimitação de objetivos do ensino, afirma que "[...] a seleção dos objetivos de ensino e a elaboração do projeto de ensino-aprendizagem estão submetidos a uma dupla determinação: a das possibilidades e a das necessidades de aprendizagem". Ressaltamos, assim, que a proposta que se segue parte de possibilidades, adequadas ou que precisarão ser ampliadas para atender às necessidades dos diferentes contextos em que possam ser aplicadas. 
Tabela 1. Possíveis Temas Gerais para a prática dos JECs: objetivos, competências, estratégias e dinâmicas (adaptado de GALATTI, 2006, p.68-70).

\begin{tabular}{|c|c|c|c|c|}
\hline Tema & Objetivos/ Competências & $\begin{array}{c}\text { Estratégias de Prática } \\
\text { Esportiva }\end{array}$ & $\begin{array}{c}\text { Dinâmicas na } \\
\text { Quadra }\end{array}$ & Exemplos \\
\hline Esporte & $\begin{array}{l}\text { Compreender o esporte enquanto um } \\
\text { Fenômeno sociocultural de múltiplas } \\
\text { Possibilidades e manifestações } \\
\text { (na configuração social, saúde coletiva, } \\
\text { econômica, política, mercadológica, } \\
\text { entre } \\
\text { outros), sem desconsiderar a prática de } \\
\text { diferentes modalidades. }\end{array}$ & $\begin{array}{l}\text { Exercícios; } \\
\text { Brincadeiras; } \\
\text { Situações de jogo; } \\
\text { Jogos pré-desportivos; } \\
\text { Jogos adaptados a partir } \\
\text { das modalidades } \\
\text { formais; Modalidades } \\
\text { formais. }\end{array}$ & $\begin{array}{l}\text { Prática de diferentes } \\
\text { Modalidades } \\
\text { eportivas - } \\
\text { não apenas } \\
\text { JECs - na sua } \\
\text { estrutura de origem e } \\
\text { atual; Construção } \\
\text { de regras. }\end{array}$ & $\begin{array}{l}\text { Praticar o basquetebol como } \\
\text { J.Naismith propôs, em suas } \\
13 \text { regras originais e } \\
\text { modificar até chegar às } \\
\text { regras atuais. } \\
\text { Festivais e Mini-torneios a } \\
\text { partir de modalidades } \\
\text { esportivas formais. }\end{array}$ \\
\hline $\begin{array}{l}\text { Jogos } \\
\text { Esportivos } \\
\text { Coletivos }\end{array}$ & $\begin{array}{l}\text { Conceituar JEC e ser capaz de jogar } \\
\text { jogos de equipe, pondo em prática os } \\
\text { valores de coletividade. }\end{array}$ & $\begin{array}{l}\text { Situações de jogo; } \\
\text { Jogos pré-desportivos; } \\
\text { Modalidades formais } \\
\text { modificadas (como os } \\
\text { jogos reduzidos); } \\
\text { Modalidades formais. }\end{array}$ & $\begin{array}{l}\text { Prática de diferentes } \\
\text { jogos pré-esportivos e } \\
\text { JECs com as } \\
\text { adaptações } \\
\text { necessárias. }\end{array}$ & $\begin{array}{l}\text { Queimadas, Pique-Bandeira, } \\
\text { Basquetebol, Handebol, } \\
\text { Futsal, Voleibol. }\end{array}$ \\
\hline $\begin{array}{l}\text { Característica } \\
\text { s comuns }\end{array}$ & $\begin{array}{l}\text { Ser capaz de reconhecer as } \\
\text { proximidades entre os JEC, observando } \\
\text { que todos têm um campo de jogo, um } \\
\text { tempo determinado, duas equipes, um } \\
\text { alvo a defender, um alvo a atacar e são } \\
\text { regidos por regras. }\end{array}$ & $\begin{array}{l}\text { Observação de espaços } \\
\text { de jogos; } \\
\text { Situações de jogo; } \\
\text { Jogos pré-desportivos; } \\
\text { Modalidades formais } \\
\text { modificadas (como os } \\
\text { jogos reduzidos); } \\
\text { Modalidades formais. }\end{array}$ & $\begin{array}{l}\text { Prática de diferentes } \\
\text { jogos pré-esportivos e } \\
\text { JECs com as } \\
\text { adaptações } \\
\text { necessárias em uma } \\
\text { mesma aula, } \\
\text { evidenciando } \\
\text { semelhanças. }\end{array}$ & $\begin{array}{l}\text { Jogos de equipe, jogos de } \\
\text { invasão (queimadas, pique } \\
\text { bandeira). }\end{array}$ \\
\hline $\begin{array}{l}\text { Princípios } \\
\text { Operacionais } \\
\text { Defensivos }\end{array}$ & $\begin{array}{l}\text { Reconhecer que há um alvo a ser } \\
\text { protegido e estabelecer estratégias } \\
\text { individuais e coletivas para } \\
\text { tal.Reconhecer que há uma equipe } \\
\text { adversária buscando aproximar-se do } \\
\text { alvo e buscar dificultar esta } \\
\text { aproximação. } \\
\text { Ter a atitude de tentar recuperar a bola } \\
\text { individual e/ou coletivamente. }\end{array}$ & $\begin{array}{l}\text { Exercícios; Situações de } \\
\text { jogo; } \\
\text { Jogos pré-desportivos; } \\
\text { Modalidades formais } \\
\text { modificadas (como os } \\
\text { jogos reduzidos); } \\
\text { Modalidades formais. }\end{array}$ & $\begin{array}{l}\text { Situações } \\
\text { imprevisíveis } \\
\text { objetivando proteger } \\
\text { o alvo, impedir a } \\
\text { progressão do } \\
\text { adversário e } \\
\text { recuperar a posse de } \\
\text { bola. }\end{array}$ & $\begin{array}{l}\text { Jogos de equipe em } \\
\text { espaços modificados, com } \\
\text { intervenções do professor } \\
\text { enfatizando a defensiva. } \\
\text { Situações de superioridade } \\
\text { de defensores para facilitar } \\
\text { a vivência da defensiva. }\end{array}$ \\
\hline $\begin{array}{l}\text { Princípios } \\
\text { Operacionais } \\
\text { Ofensivos }\end{array}$ & $\begin{array}{l}\text { Reconhecer que há um alvo a ser } \\
\text { atingido e estabelecer estratégias } \\
\text { individuais e coletivas para tal. } \\
\text { Reconhecer que é necessário } \\
\text { aproximar-se do alvo e que há colegas } \\
\text { que compõem uma equipe. Saber } \\
\text { preservar a bola em posse de sua } \\
\text { equipe. }\end{array}$ & $\begin{array}{l}\text { Exercícios; Situações de } \\
\text { jogo; } \\
\text { Jogos pré-desportivos; } \\
\text { Modalidades formais } \\
\text { modificadas (como os } \\
\text { jogos reduzidos); } \\
\text { Modalidades formais. }\end{array}$ & $\begin{array}{l}\text { Situações de } \\
\text { imprevisibilidade onde } \\
\text { as ações de manter a } \\
\text { posse de bola, } \\
\text { aproximar-se do alvo } \\
\text { e finalizar sejam } \\
\text { exigidas. }\end{array}$ & $\begin{array}{l}\text { Jogos de equipe em } \\
\text { espaços modificados, com } \\
\text { intervenções do professor } \\
\text { enfatizando a ofensiva. } \\
\text { Situações de superioridade } \\
\text { de atacantes para facilitar a } \\
\text { vivência da ofensiva. }\end{array}$ \\
\hline $\begin{array}{l}\text { Princípios } \\
\text { Operacionais } \\
\text { de Transição }\end{array}$ & $\begin{array}{l}\text { Reconhecer que, ao recuperar uma bola } \\
\text { na defesa é necessário organizar-se } \\
\text { taticamente - individual e coletivamente } \\
\text { - para organizar o ataque. Reconhecer } \\
\text { que, ao perder uma bola ou concluir um } \\
\text { ataque com sucesso é necessário } \\
\text { organizar-se taticamente - individual e } \\
\text { coletivamente - para organizara defesa. }\end{array}$ & $\begin{array}{l}\text { Exercícios; Situações de } \\
\text { jogo; } \\
\text { Jogos pré-desportivos; } \\
\text { Modalidades formais } \\
\text { modificadas (como os } \\
\text { jogos reduzidos); } \\
\text { Modalidades formais. }\end{array}$ & $\begin{array}{l}\text { Situações de } \\
\text { imprevisibilidade nas } \\
\text { quais os alunos } \\
\text { vivenciem situações } \\
\text { de passagem da } \\
\text { defesa para o ataque } \\
\text { e do ataque para a } \\
\text { defesa. }\end{array}$ & $\begin{array}{l}\text { Jogos de equipe em } \\
\text { espaços modificados, com } \\
\text { intervenções do professor } \\
\text { enfatizando a transição. } \\
\text { Situações de superioridade } \\
\text { de atacantes ou defensores } \\
\text { para facilitar a vivência da } \\
\text { transição. }\end{array}$ \\
\hline $\begin{array}{l}\text { Regras de } \\
\text { Ação }\end{array}$ & $\begin{array}{l}\text { Saber comportar-se taticamente em } \\
\text { jogos de equipe a partir da estrutura e } \\
\text { lógica comum. Saber ocupar os espaços } \\
\text { da quadra. Saber posicionar-se para } \\
\text { receber a bola de um companheiro. } \\
\text { Saber posicionar-se para pressionar um } \\
\text { adversário com posse da bola }\end{array}$ & $\begin{array}{l}\text { Situações de jogo; } \\
\text { Jogos pré-desportivos; } \\
\text { Modalidades formais } \\
\text { modificadas (como os } \\
\text { jogos reduzidos); } \\
\text { Modalidades formais. }\end{array}$ & $\begin{array}{l}\text { Situações de } \\
\text { imprevisibilidade onde } \\
\text { a organização tática } \\
\text { individual e coletiva } \\
\text { seja exigida. }\end{array}$ & $\begin{array}{l}\text { Jogos com diversos alvos; } \\
\text { Jogos com mais de duas } \\
\text { equipes }\end{array}$ \\
\hline $\begin{array}{l}\text { Fundamentos } \\
\text { Comuns }\end{array}$ & $\begin{array}{l}\text { Reconhecer a existência dos cinco } \\
\text { fundamentos comuns aos JEC - } \\
\text { controle de corpo, manejo de bola, } \\
\text { passe, drible e finalização - e tê-los } \\
\text { como recurso aliado á tática. }\end{array}$ & $\begin{array}{l}\text { Jogos, brincadeiras, } \\
\text { exercícios. }\end{array}$ & $\begin{array}{l}\text { Situações } \\
\text { preferencialmente } \\
\text { imprevisíveis que } \\
\text { focalizem o(s) } \\
\text { fundamento (s). }\end{array}$ & $\begin{array}{l}\text { Pegas, Estafetas, Passa 10, } \\
\text { drible entre obstáculos, } \\
\text { jogos com alvos, entre } \\
\text { outros. }\end{array}$ \\
\hline
\end{tabular}

De forma a sinalizar para as temáticas sugeridas para a elaboração de um LD em Educação Física, tendo por conteúdos central os JECs, apresentados nas tabelas 1 e 2 dezesseis temas que buscam apresentar o esporte como fenômeno, os JECs em suas características comuns e a partir de algumas modalidades específicas, sendo selecionados o basquetebol, futsal, handebol e voleibol. Os temas foram selecionados e desenvolvidos sendo considerados os referenciais técnico-tático e sócio-afetivo, buscando proporcionar a aprendizagem conceitual do esporte e dos JECs, as características técnico-táticas e estratégias de vivência, assim como possibilidades de aprendizagem social que a prática esportiva favorece quando bem orientada. 
Tabela 2. Possíveis temas específicos para a prática dos JECs: objetivos, competências, estratégias e dinâmicas (adaptado de GALATTI, 2006, p.70-71).

\begin{tabular}{|c|c|c|c|c|}
\hline Tema & Objetivos/ Competências & $\begin{array}{c}\text { Estratégias de Prática } \\
\text { Esportiva }\end{array}$ & $\begin{array}{c}\text { Dinâmicas na } \\
\text { Quadra }\end{array}$ & Exemplos \\
\hline O Basquetebol & \multirow{4}{*}{$\begin{array}{l}\text { Conhecer a história, as regras } \\
\text { básicas e lógica de cada } \\
\text { modalidade, focando agora suas } \\
\text { especificidades, ainda que de forma } \\
\text { introdutória. }\end{array}$} & \multirow{4}{*}{$\begin{array}{l}\text { Exercícios; Situações de } \\
\text { jogo; } \\
\text { Modalidade formal } \\
\text { modificada; } \\
\text { Modalidades formais. }\end{array}$} & \multirow{4}{*}{$\begin{array}{l}\text { Vivência da } \\
\text { modalidade } \\
\text { específica dentro } \\
\text { das condições } \\
\text { psico-fisiológicas do } \\
\text { aluno de praticar e } \\
\text { compreender o jogo. }\end{array}$} & $\begin{array}{l}\text { Basquetebol formal e } \\
\text { adaptado. }\end{array}$ \\
\hline O Handebol & & & & $\begin{array}{l}\text { Handebol formal e } \\
\text { adaptado. }\end{array}$ \\
\hline O Futsal & & & & $\begin{array}{l}\text { Futsal formal e } \\
\text { adaptado. }\end{array}$ \\
\hline O Voleibol & & & & $\begin{array}{l}\text { Voleibol formal e } \\
\text { adaptado. }\end{array}$ \\
\hline $\begin{array}{l}\text { Conhecendo } \\
\text { outras } \\
\text { modalidades } \\
\text { pelo mundo. }\end{array}$ & $\begin{array}{l}\text { Conhecer outras modalidades não } \\
\text { praticadas tradicionalmente no } \\
\text { Brasil e ser capaz de associá-las a } \\
\text { questões culturais. }\end{array}$ & $\begin{array}{l}\text { Exercícios; Situações de } \\
\text { jogo; } \\
\text { Jogos pré-desportivos; } \\
\text { Modalidades formais } \\
\text { modificadas; } \\
\text { Modalidades formais. }\end{array}$ & $\begin{array}{l}\text { Vivência de } \\
\text { modalidades } \\
\text { específicas } \\
\text { provenientes de } \\
\text { outros contextos } \\
\text { culturais, com ou } \\
\text { sem adaptações. } \\
\end{array}$ & $\begin{array}{l}\text { Rúgbi, pólo aquático, } \\
\text { beisebol, entre } \\
\text { outros, no formato } \\
\text { oficial e adaptado. }\end{array}$ \\
\hline Curiosidades & $\begin{array}{l}\text { Dar ao aluno subsídios para } \\
\text { observar e analisar momentos, } \\
\text { atitudes e outras situações curiosas } \\
\text { nos JECs profissionais. }\end{array}$ & \multirow{4}{*}{$\begin{array}{l}\text { Interferência verbal do } \\
\text { professor, remetendo-se } \\
\text { à prática dos alunos ou } \\
\text { ao livro didático. }\end{array}$} & \multirow{4}{*}{$\begin{array}{l}\text { Ao longo das } \\
\text { atividades práticas, } \\
\text { aproveitando as } \\
\text { situações surgidas } \\
\text { ao longo das } \\
\text { mesmas, reportar-se } \\
\text { a fatos curiosos e/ou } \\
\text { históricos, assim } \\
\text { como reforçar para o } \\
\text { aluno metáforas } \\
\text { existentes entre os } \\
\text { JECs e a vida } \\
\text { comunitária. }\end{array}$} & \multirow{4}{*}{$\begin{array}{l}\text { Aproveitar-se de } \\
\text { ações técnicas dos } \\
\text { alunos para reportar- } \\
\text { se a atletas da } \\
\text { atualidade ou do } \\
\text { passado. } \\
\text { Quando os alunos } \\
\text { demonstrarem } \\
\text { dificuldade em } \\
\text { resolver um problema } \\
\text { coletivo do jogo, } \\
\text { mostra proximidades } \\
\text { com a vida em } \\
\text { sociedade e ressaltar } \\
\text { valores como } \\
\text { respeito e } \\
\text { fraternidade, } \\
\text { destacando ações } \\
\text { cooperativas. }\end{array}$} \\
\hline $\begin{array}{l}\text { Valores de } \\
\text { comportament } \\
\text { o }\end{array}$ & $\begin{array}{l}\text { Ser capaz de observar, analisar e } \\
\text { discutir o esporte e as situações } \\
\text { vivenciadas na prática dos JECs, } \\
\text { elucidando valores. Ser capaz de } \\
\text { estabelecer relações pessoais de } \\
\text { valor - tais como cooperação, } \\
\text { empatia e respeito - para o } \\
\text { desenvolvimento de um jogo } \\
\text { coletivo, estabelecendo metáforas } \\
\text { com a vida. }\end{array}$ & & & \\
\hline $\begin{array}{l}\text { Fatos } \\
\text { Históricos }\end{array}$ & $\begin{array}{l}\text { Conhecer momentos importantes } \\
\text { para o desenvolvimento dos JECs } \\
\text { no Brasil. }\end{array}$ & & & \\
\hline $\begin{array}{l}\text { Personagens } \\
\text { dos JEC do } \\
\text { Brasil }\end{array}$ & $\begin{array}{l}\text { Reconhecer a importância de alguns } \\
\text { atletas, técnicos para o crescimento } \\
\text { dos JEC no Brasil }\end{array}$ & & & \\
\hline
\end{tabular}

\section{O Método: a seqüência didática como balizadora da organização de temas e conteúdos}

Considerando a variedade de temas que os JECs permitem abordar - tais quais invariantes, princípios operacionais, aspectos técnicos, táticos, valores de comportamento, histórico e regras - e buscando organizá-los em um processo de ensino, selecionamos como método o modelo de seqüência didática (SD) apresentada por Dolz, Noverraz \& Schneuwly (2004). Após a organização da seqüência didática, esta foi utilizado para a elaboração do livro didático sobre JECs. Para melhor tratarmos de seqüência didática, cabe apresentarmos o esquema elaborado pelos autores:

A apresentação da situação é o momento no qual o objeto de ensino principal é apresentado aos alunos, sendo que a partir daquele estes deverão cumprir uma primeira atividade, que será a produção inicial. "Esta etapa permite ao professor avaliar as capacidades já adquiridas e ajustar as atividades e exercícios previstos na seqüência às possibilidades e dificuldades reais de uma turma". (DOLZ, NOVERRAZ \& SCHNEUWLY, 2004, p.99)

Já os módulos vão apresentando de forma seqüencial o objeto de estudo, em nosso caso os JECs, sendo potencializados determinados conteúdos de acordo com a mediação do professor, a partir do que foi apresentado pelo aluno da produção inicial.

A produção final, por sua vez, é o momento em que "o aluno pode pôr em prática os conhecimentos adquiridos e, com o professor, medir os progressos alcançados. A produção final serve, também, para uma avaliação de tipo somativo, que incidirá sobre os aspectos trabalhados durante a seqüência". (DOLZ, NOVERRAZ \& SCHNEUWLY, 2004, p.99)

A organização dos conteúdos está entre as tarefas relacionadas ao professor ao liderar um processo pedagógico de ensino, vivência e 
aprendizagem no esporte na perspectiva de formação integral do aluno, como sinaliza Galatti (2006, p.36):

[...] à Pedagogia do Esporte, quando no trato com modalidades coletivas, cabe organizar, sistematizar, aplicar e avaliar procedimentos pedagógicos a fim de formar jogadores inteligentes, ou seja, capazes de lidar com os problemas do jogo; e cooperativos, assim como exige um jogo esportivo coletivo, estimulando ainda a transcendência dos conteúdos e atitudes tomadas da quadra para além desta, através de um processo educacional para e pelo o esporte.

Uma vez apresentado os JECs, seus conteúdos, temas de abordagem e sua distribuição no processo a partir do modelo de seqüência didática, cabe apresentarmos 0 recurso didático apontado neste artigo como facilitador para o professor e aluno: o livro didático.

\section{O livro didático acerca dos JECs: apresentando os conteúdos em uma seqüência didática}

A partir do conceito de Seqüência Didática apontada na metodologia e nas características dos JECs já citadas neste artigo, estruturamos o Livro Didático para Educação Física, com o objetivo específico de trabalhar com tema Jogos Esportivos Coletivos, sinalizando para a seguinte organização, disposta no quadro 2:

Figura 1. Esquema de Seqüência Didática. (DOLZ, NOVERRAZ \& SCHNEUWLY, 2004, p.98)



Esta seqüência didática apresenta-se com um pilar para a construção de um livro didático que trate dos JECs, considerando a complexidade destas modalidades e partindo dos princípios de Bayer quanto às proximidades entre elas. Destacamos que a utilização do LD se daria em concomitância às aulas práticas, podendo ser feita tanto no local de aula com em casa, sempre pelos alunos e sendo o professor um mediador, potencializando os recursos didáticos disponíveis, como destaca Galatti (2006, p.82):

[...] o LD é um instrumento do processo de ensino e aprendizagem mediador da relação professor e aluno dentro de uma disciplina específica da educação formal, que é escolhido e mediado pelo professor e não apenas lido, mas usado pelo aluno. Assim, não basta um bom material didático, é necessária uma formação adequada ao professor para que este possa utilizá-lo a partir de seu planejamento e ao longo da construção de sua prática, e não como o seu planejamento e a sua prática.

Considerando a importância e autonomia do professor ao liderar ao processo e respeitando a seqüência didática apresentada, sugerimos que um livro didático tematizando os JECs se inicie com uma abordagem do esporte de forma mais geral, tratando das diversas possibilidades de manifestação do fenômeno; a seguir, são apresentados os JECs, com conceitos e exemplos, assim como informações e atividades interativas que levassem o aluno a observar as características comuns deste conjunto de modalidades esportivas.

Pelo modelo de seqüência didática (SD) apresentada por Dolz, Noverraz \& Schneuwly (2004), após esta abordagem inicial, ou apresentação da situação, o LD deve trazer uma atividade a ser realizada pelos alunos como uma primeira produção, a partir da qual o professor analisará quais os conhecimentos que os alunos já demonstram ter em relação aos JECs, organizando assim as aulas que se seguem. Sugerimos, ainda, que o professor observe também uma produção inicial prática, elaborando um jogo coletivo, como um pré-esportivo, através do qual possa observar o comportamento técnicotático e sócio-afetivo dos alunos. 
Após a apresentação dos temas, o LD passa a ser organizado por módulos, sendo por nós sugeridos dois para o trato com os JECs: um primeiro que trate dos princípios operacionais, das regras de ação e dos fundamentos comuns; no segundo, seriam apresentadas informações sobre história, técnica e tática de modalidades específicas, sendo sugeridas aquelas de maior apelo cultural em nosso país: basquetebol, handebol, futebol e voleibol. Entretanto, outras modalidades são também apresentadas, embora sem maior aprofundamento.

Figura 2. Módulos, Temas e Elementos de Apoio do Livro Didático em Jogos Esportivos Coletivos: a seqüência didática (GALATTI, 2006, p.97).

\begin{tabular}{|l||l||}
\hline Livro Didático para Jogos Esportivos Coletivos: \\
\hline Apresentação da situação: \\
\hline Esporte \\
\hline Jogos Esportivos Coletivos \\
\hline Características comuns \\
\hline Produção Inicial \\
\hline Módulo 1: JEC \\
\hline Princípios Operacionais Defensivos \\
\hline Princípios Operacionais Ofensivos \\
\hline Princípios Operacionais de Transição \\
\hline Regras de Ação \\
\hline Fundamentos Comuns \\
\hline Módulo 2: Modalidades Especificas: \\
\hline O Basquetebol \\
\hline O Handebol \\
\hline O Futsal \\
\hline O Voleibol \\
\hline Conhecendo outras modalidades pelo mundo. \\
\hline Produção Final \\
\hline
\end{tabular}

É possível observar, na figura 2, a presença de um segundo bloco integrado a toda a seqüência didática, denominado "Elementos de Apoio e de Potencial Valor Sócio-Educativo", que busca atender ao referencial sócio-educativo através de atividades interativas que questionem sobre comportamentos aceitáveis ou não em quadra ou na torcida, apresenta grandes atletas e curiosidades da história do esporte e estimula a análise das mesmas, dentre outras estratégias.

Com a proposição e descrição de um livro didático para o trato com JECs, a partir de uma estrutura coerente - o que se fez possível a partir da elaboração de uma seqüência didática - que este se constitui em um mediador entre as teorias relacionadas aos JECs e as crianças que praticam e estudam tais modalidades.

O livro didático pode auxiliar o professor no desenvolvimento do processo de ensino, vivência e aprendizagem do esporte, desde que utilizado a partir de um conhecimento sólido do tema a ser ensinado (neste estudo, os JECs) e dos procedimentos pedagógicos envolvidos na oferta da vivência e na própria utilização do auxiliar pedagógico aqui investigado, o LD. Desta forma, ressaltamos a importância do professor e a relevância de uma formação de qualidade e que estimule a uma observação crítica da realidade para que se possa intervir na mesma.

\section{Considerações Finais}

O presente estudo teve como objetivo apresentar uma proposta concreta para 0 trato com JECs nas aulas de Educação Física ao propor um livro didático que trate das questões teóricas relativas a este tema, que devem ser agregadas à prática do professor, sendo destacado o ensino formal, o que não descarta sua aplicação no ensino não formal.

Este não é, no entanto, um estudo conclusivo, ao contrário, respeitando a instabilidade do conhecimento, sugere novas discussões acadêmicas, novos temas para futuros estudos 
acadêmicos e subsídios para a construção de novos modelos ou seqüências didáticas para o trato com o esporte nas aulas de Educação Física, como nas sugestões que se seguem:

- Discutir com maior profundidade acerca de quais são os pressupostos paradigmáticos que regem as pesquisas em esporte;

- Esclarecimento de quais são os pressupostos filosóficos que regem a organização e prática pedagógica do professor de esportes;

- Refletir de forma permanente como se ensinar o esporte, muito embora o foco principal deste processo nos parece claro: o aluno.

- O aluno, por sua vez, faz parte de um sistema composto por outros alunos, professores, pais e outras pessoas que se relacionam no ambiente esportivo; mais, este mesmo aluno freqüenta outros ambientes: como ajudar prepará-lo para uma sociedade plural?

- Qual a repercussão de um livro didático na educação física? Até que ponto será necessário um trabalho de capacitação dos professores para que estes utilizem este novo facilitador de forma autônoma, sendo capaz de escolher quando e o que utilizar ao longo de suas aulas?

Mostra-se também possível e necessário novos projetos que envolvam LD e Educação Física, visto que são vastos os conteúdos desta disciplina passíveis de ter uma abordagem teórica voltada para os alunos, tais como as lutas, as diferentes ginásticas, artes circenses, jogos populares, introdução ao treinamento esportivo, diferentes modalidades esportivas e enfoques ao fenômeno esporte, dentre outros temas.

Neste artigo abordamos a partir de referencial bibliográfico os JECs, sinalizando para um novo material didático a ser incorporado ao processo de ensino, vivência e aprendizagem dos JECs: 0 livro didático, na expectativa que este seja mais um recurso agregado à prática docente e não um determinante da mesma.

Para fazer a transição de uma revisão bibliográfica para a proposição de um livro didático em educação física para $\circ$ trato com JECs, recorremos a autores especialistas no tema, tendo como base a área da lingüística, na qual também conhecemos o conceito de Seqüência Didática, que foi determinante para a organização dos conteúdos a serem tratados no LD sobre JECs.

Vale considerarmos, ainda, a possibilidade de adaptações para a adequação deste material para outros instrumentos, sejam impressos ou em outros suportes (audiovisuais, softwares, CD-
Rom, Internet, etc.), como observa Choppin (2004).

O presente artigo tem a preocupação de contribuir com as pesquisas em pedagogia do esporte e didática, buscando também contribuir para prática pedagógica, diminuindo a distância entre a produção acadêmica e o que lá acontece. A partir do LD, considerando-o um mediador entre a criança e os JECs, o LD ajuda o professor na organização dos conteúdos do trabalho, sem substituí-lo, tampouco sem diminuir sua importância ao longo do processo de ensino aprendizagem, uma vez que ele continuará a ser o principal mediador do processo, uma vez que sua formação profissional e autonomia deve permitir ao profissional potencializar este material.

\section{Referências}

BALBINO, Hermes Ferreira. Jogos desportivos coletivos e os estímulos das inteligências múltiplas: bases para uma proposta em pedagogia do esporte. 2001. 142f. Dissertação (Mestrado em Educação Física) - Faculdade de Educação Física, Universidade Estadual de Campinas, Campinas.

BETTI, Mauro. Educação física e sociedade. São Paulo: Movimento, 1991.

BETTI, Mauro. Ensino de primeiro e segundo graus: educação física para quê? Revista Brasileira de Ciências do Esporte, v. 13, n.2, p. 282-287, 1992.

\section{BAYER, Claude. O Ensino dos Desportos} Coletivos. Editions Vigot, Paris, 1994

CHOPPIN, Alain. História dos livros e das edições didáticas: sobre o estado da arte. In: Revista Educação e Pesquisa, São Paulo. V.30, n.3, p. 549-566, set./dez. 2004.

DARIDO, Suraya Cristina; SANCHEZ NETO, Luiz. Os Conteúdos da Educação Física na Escola. In: DARIDO, Suraya Cristina.; RANGEL, Irene Conceição Andrade. Educação Física na Escola: implicações para a prática pedagógica. Guanabara Koogan, Rio de Janeiro, 2005. p. 224.

DOLZ, Joaquim; NOVERRAZ, Michéle; SCHNEUWLY, Bernard. Seqüências didáticas para o oral e a escrita: apresentação de um procedimento. In: Rojo, Roxane Helena; Cordeiro, Glaís Sales (orgs, trads) Gêneros Orais e

Escritos na Escola. Tradução de trabalhos de Bernard Schneuwly, Joaquim Dolz \& colaboradores, p. 95-128. Campinas: Mercado de Letras :2004. 
FERREIRA, Henrique Barcelos. Pedagogia do esporte: identificação, discussão e aplicação de procedimentos pedagógicos no processo de ensino-vivência e aprendizagem da modalidade basquetebol. 2009. 240f. Dissertação (Mestrado em Educação Física)-Faculdade de Educação Física. Universidade Estadual de Campinas, Campinas, 2009.

FERREIRA, Henrique Barcelos.; GALATTI, Larissa Rafaela; PAES, Roberto Rodrigues. Pedagogia do Esporte: considerações pedagógicas e metodológicas no processo de ensino e aprendizagem do basquetebol. In: PAES, Roberto Rodrigues; BALBINO, Hermes Ferreira; Pedagogia do Esporte: contextos e perspectivas. Rio de Janeiro: Guanabara Koogan, 2005.

GALATTI, Larissa Rafaela. Pedagogia do Esporte: o livro didático como um mediador no processo de ensino e aprendizagem de jogos esportivos coletivos. 2006. 139f. Dissertação (Mestrado em Educação Física)-Faculdade de Educação Física. Universidade Estadual de Campinas, Campinas, 2006.

GALATTI, Larissa Rafaela et. al. Pedagogia do Esporte: procedimentos pedagógicos aplicados aos jogos esportivos coletivos. Revista Conexões, Campinas, v. 6, n. especial, 2008. p. 404-415. Disponível em: $<$ http://polaris.bc.unicamp.br/seer/fef/viewarticle.p hp?id=319\&layout=abstract $>$ Acesso em: 12 mai. 2009

GARGANTA, Julio. Para uma teoria dos jogos desportivos coletivos. In: GRAÇA, Armândio.; OLIVEIRA, J. (Eds.). 0 ensino dos jogos desportivos coletivos. 2. ed. Lisboa: Universidade do Porto, 1995. p. 11-25.

\section{KUNZ, Elenor. Transformação Didático-}

Pedagógica do Esporte. ljuí, Sedigraf, 1997.

LAJOLO, Marisa. Livro Didático: um (quase) manual do usuário. In: Em Aberto, Brasília, n.69, ano 16. 1996. p. 3-9.

MUNAKATA, Kazumi (1999) Livro didático: produção e leituras. In: ABREU, Márcia (org). Leitura, história e história da leitura.

Campinas: Mercado de Letras/ALB. p. 577-595

PAES, Roberto Rodrigues. Aprendizagem e competição precoce: o caso do basquetebol. 3.ed. Campinas: Ed. da Unicamp, 1997.

PAES, Roberto Rodrigues. Educação física escolar: o esporte como conteúdo pedagógico do ensino fundamental. Canoas: Ed. Ulbra, 2001.
PAES, Roberto Rodrigues. A pedagogia do esporte e os jogos coletivos. In: ROSE JR. Esporte e atividade física na infância e adolescência. São Paulo: Artmed, 2002. p. 8998.

ROJO, Roxane Helena. Praticando os PCNs: dos Parâmetros Curriculares Nacionais à Prática de Sala de Aula, durante o 9 InPLA -

Intercâmbio de Pesquisas em Lingüística Aplicada, 01/05/1999, LAEL/PUC-SP

ROSÁRIO, Luis Fernando Rocha, DARIDO, Suraya Cristina. A sistematização dos conteúdos da educação física na escola: a perspectiva dos professores experientes. Motriz, Rio Claro, v.11 n.3 p.167-178, set./dez. 2005

SANTANA, Wilton Carlos de. Pedagogia do esporte na infância e complexidade. In: PAES, Roberto Rodrigues; BALBINO, Hermes Ferreira.

Pedagogia do esporte: contextos e perspectivas. Rio de Janeiro: Guanabara Koogan, 2005. p.1-22.

TANI, Go, SANTOS, Sueli e MEIRA JR., Cássio de Miranda. O Ensino da Técnica e a Aquisição de Habilidades Motoras no Desporto. In: TANI, Go, BENTO, Jorge Olímpio e PETERSEN, Ricardo Demétrio de Souza. Pedagogia do Desporto. Rio de Janeiro: Guanabara Koogan, 2006. p.227-239.

TEODORESCU, Libaneo Problemas de teoria e metodologia nos jogos desportivos. Lisboa:

Endereço:

Larissa Rafaela Galatti

Rua Campos Sales, 348 Centro

Cosmópolis SP Brasil

13150-000

Telefone: (19)3872.2718 e (19)9186.7478

e-mail: lagalatti@yahoo.com.br

Recebido em: 20 de novembro de 2009.

Aceito em: 28 de abril de 2010.

Motriz. Revista de Educação Física. UNESP, Rio Claro, SP, Brasil - elSSN: 1980-6574 - está licenciada sob Licenca Creative Commons 